\title{
The Humpbacked Species Richness-Curve: A Contingent Rule for Community Ecology
}

\author{
John H. Graham ${ }^{1}$ and Jeffrey J. Duda ${ }^{2}$ \\ ${ }^{1}$ Department of Biology, Berry College, Mount Berry, GA 30149, USA \\ ${ }^{2}$ Western Fisheries Research Center, U.S. Geological Survey, Seattle, WA 98115, USA
}

Correspondence should be addressed to John H. Graham, jgraham@berry.edu

Received 1 January 2011; Revised 22 April 2011; Accepted 23 May 2011

Academic Editor: Shibu Jose

Copyright ( 2011 J. H. Graham and J. J. Duda. This is an open access article distributed under the Creative Commons Attribution License, which permits unrestricted use, distribution, and reproduction in any medium, provided the original work is properly cited.

\begin{abstract}
Functional relationships involving species richness may be unimodal, monotonically increasing, monotonically decreasing, bimodal, multimodal, U-shaped, or with no discernable pattern. The unimodal relationships are the most interesting because they suggest dynamic, nonequilibrium community processes. For that reason, they are also contentious. In this paper, we provide a wide-ranging review of the literature on unimodal (humpbacked) species richness-relationships. Though not as widespread as previously thought, unimodal patterns of species richness are often associated with disturbance, predation and herbivory, productivity, spatial heterogeneity, environmental gradients, time, and latitude. These unimodal patterns are contingent on organism and environment; we examine unimodal species richness-curves involving plants, invertebrates, vertebrates, plankton, and microbes in marine, lacustrine, and terrestrial habitats. A goal of future research is to understand the contingent patterns and the complex, interacting processes that generate them.
\end{abstract}

\section{Introduction}

For decades, ecologists have searched for general principles that hold across the entire natural world [1-4]. Humpbacked, or unimodal, relationships between species richness and productivity and between species richness and disturbance are examples of such attempts to find general principles in ecology. These attempts arose following Hutchinson's [5] famous meditation regarding the enormous number of animal species. Yet, the form of species richness-productivity relationships [6-9] and species richness-disturbance relationships $[10,11]$ has generated much controversy, myriad models, and few generalizations. The patterns we see are diverse, and unimodal species richness-curves are not the universal pattern ecologists had hoped for 50 years ago. Nevertheless, they occur often enough to be of interest and may be considered "contingent rules" [2]—contingent on organism and environment.

The number of species in an ecological community (i.e., its species richness) is one of a community's defining characteristics, along with the abundances of those species. Some communities, especially those in the tropics, may contain thousands of species, while others, especially in extreme environments at high latitudes and altitudes, may contain only tens of species. Understanding why one community contains more species than another is a central problem in community ecology. Nevertheless, the incredible complexity of ecological interactions guarantees that the species richness-problem is strikingly difficult. In this paper, we provide a wideranging review of the literature, including its history and emerging new theories, on one aspect of the species richnessproblem-humpbacked species richness-relationships.

A humpbacked species richness-curve is a functional relationship between species richness on the one hand and one of several characteristics of ecological communities on the other, including disturbance, predation intensity, productivity, environmental gradients, time, and latitude. At least five different categories of functional relationship are possible: unimodal, multimodal, monotonically increasing, monotonically decreasing, or no relationship (Figure 1). U-shaped and J-shaped functions, though rare, are also possible [12] and probably represent mixtures of monotonically 


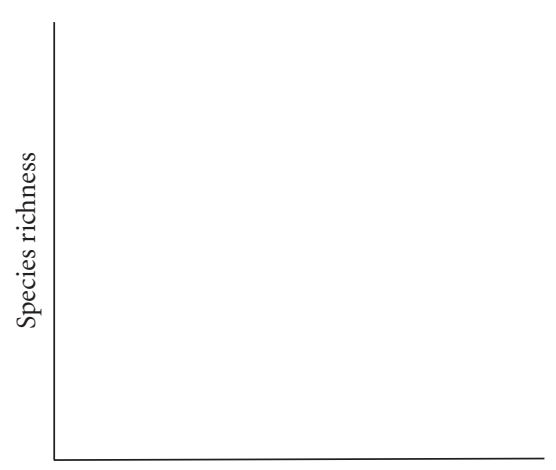

Gradient

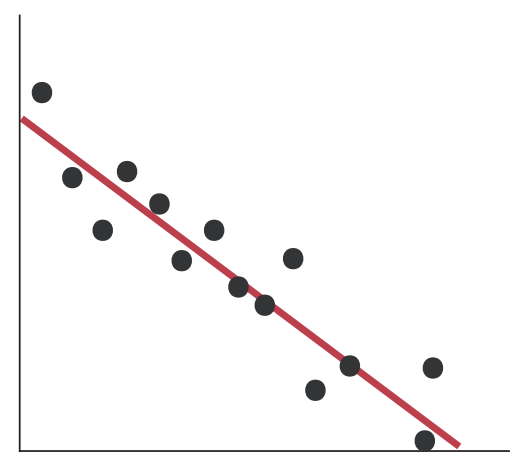

(c)

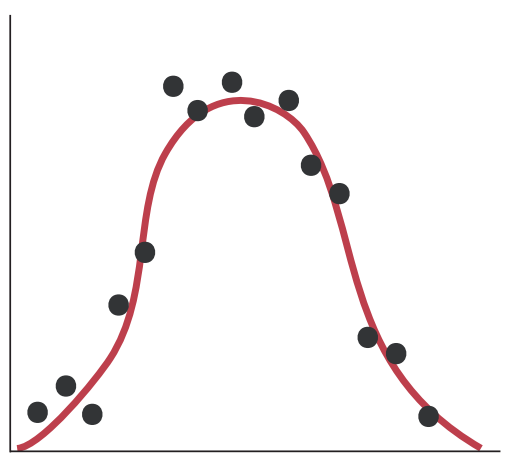

(a)

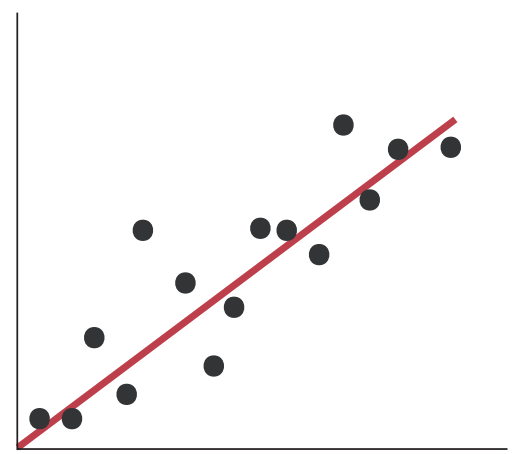

(d)

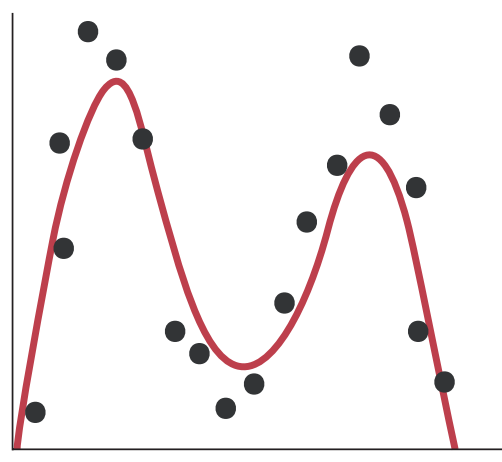

(b)

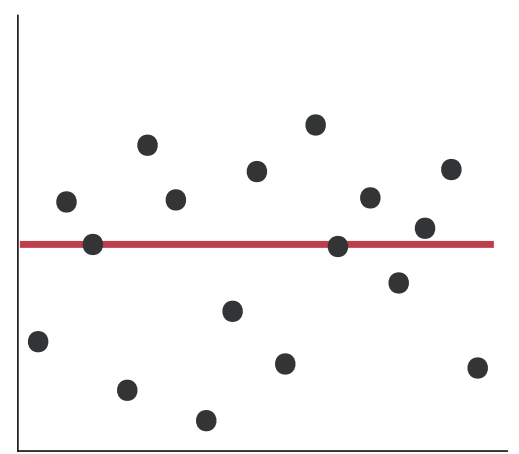

(e)

FIGURE 1: Functional relationships involving species richness: (a) unimodal "humpbacked", (b) multimodal, (c) monotonically decreasing, (d) monotonically increasing, and (e) no relationship.

increasing and decreasing functions. Whittaker [7] classifies U-shaped functions as unimodal, but they are quite different. Moreover, they have no theoretical basis in the species richness-literature and we do not consider them further.

Unimodal functions (Figure 2(a)) should not be confused with unimodal probability (frequency) distributions (Figure 2(b)). A mode in the ordinary sense is a value that either appears most frequently in a sample or is the most likely value of a probability mass function. In contrast, the "mode" of a unimodal function is not its most frequent value. A species richness-function $f(x)$ is unimodal if it is monotonically increasing for $x \leq m$ and monotonically decreasing for $x \geq m$, where $m$ is the value of the mode. Most humpbacked species richness-curves are unimodal functions. Nevertheless, at least one species richness-relationship is a probability (frequency) distribution-counts of individual species of a particular body size [13].

Given that unimodal species richness-relationships are contingent upon both organism and environment, it is natural to ask what kinds of organisms display them, and in what environments do they occur? What causes unimodal species richness-relationships, and what processes generate them? Can we predict when and where they will occur?

We begin with a disclaimer: our review is nonexhaustive and focuses mostly on local species richness-functions, not regional or global ones and not probability distributions. Thus, we discuss elevational, depth, and narrow latitudinal gradients, but not global latitudinal gradients. We discuss species richness among communities within ecoregions, but not among the ecoregions themselves. Most of the ecological communities we discuss share species, which cannot be said of communities in widely different ecoregions.

We begin by discussing the six common processes, or agents, that generate unimodal species richness-curves. These are (1) disturbance, (2) predation and herbivory, (3) productivity, (4) environmental gradients (e.g., $\mathrm{pH}$, moisture, depth, and elevation), (5) time, and (6) latitude. These relationships encompass the two kinds of gradients discussed by Huston [14]: (1) resource gradients and (2) regulator gradients. These gradients differ in the following way: resources, such as nutrients, are depleted by organisms, whereas regulators, such as temperature and depth, regulate the physiology of organisms.

In addition to the processes that generate unimodal species richness-curves, the scale of study, fine or coarse, can modulate the observed shape of a species richness-curve. A unimodal curve may appear at one scale, while a monotonically increasing curve may appear at a different one. Consequently, we address alpha, beta, and gamma diversities, as well as the concepts of grain, focus, and extent.

In addition to the problem of scale, certain taxonomic and functional groups of organisms are more likely to display unimodal curves in particular habitats. We discuss unimodal species richness-curves of plants, invertebrates, vertebrates, 


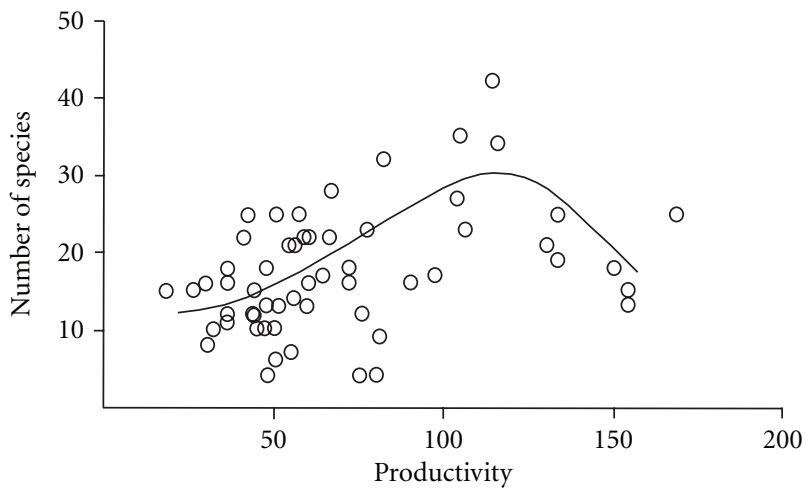

(a)

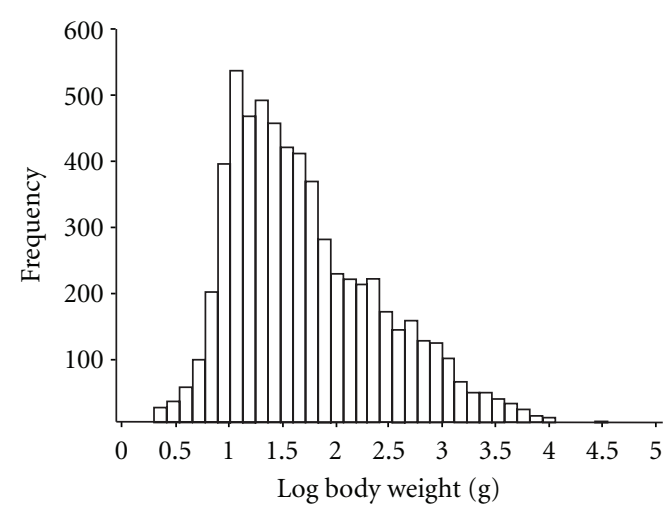

(b)

FIGURE 2: Unimodal functions and probability distributions. (a) Species richness of tropical mammals as a function of productivity (redrawn from Rosenzweig and Abramsky [39]). (b) Body mass distribution of the world's mammals (redrawn from Gardezi and da Silva [13]).

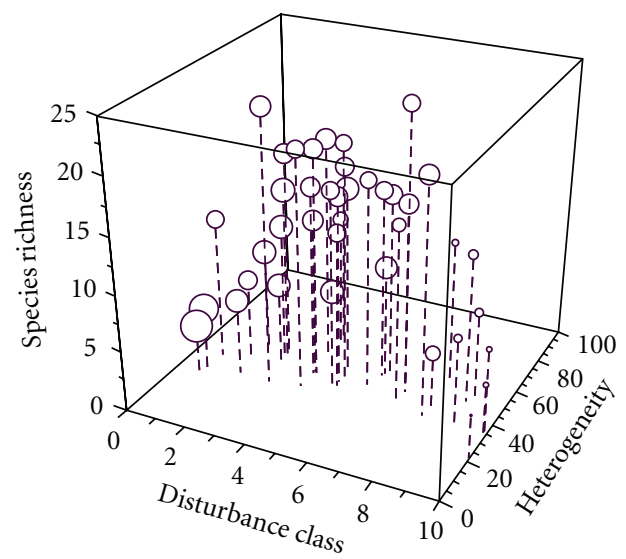

FIGURE 3: Relationships among ant species richness, disturbance class, spatial heterogeneity, and productivity (normalized difference vegetation index (NDVI), which is proportional to bubble size) for 40 sites at Fort Benning, Georgia. Species richness and spatial heterogeneity peak with intermediate disturbance. NDVI decreases monotonically with increasing disturbance. After Graham et al. [32].

plankton, and microbes in marine, lacustrine, and terrestrial habitats.

Finally, we discuss mathematical and statistical considerations related to species richness-curves. What constitutes acceptable evidence that a species richness-curve is unimodal? What sampling strategies are most likely to reveal a unimodal relationship if it is there?

\section{Functional Relationships}

2.1. Species Richness and Disturbance. According to the intermediate disturbance hypothesis, the number of species in a community is greatest when some intermediate intensity, frequency, scale, or duration of disturbance is present [11, 15-19]. Chesson [20] describes this as a consequence of either the storage effect or relative nonlinearity. The storage effect involves trade-offs between competition and dispersal. Disturbance reduces the density of competitive species having poor dispersal, thereby creating opportunities for less competitive ones having good dispersal. With intermediate disturbance, both groups of species coexist; competitively dominant species cannot monopolize all of the resources and pioneering species can still find sites to colonize. Relative nonlinearity occurs when the population growth rate of one species is a nonlinear function of the population growth rate of another species. Both of these theoretical models describe conditions for species coexistence.

Diversity of sedentary organisms, such as tropical forest plants [18,21], corals [18], and alpine plants [22], often supports the intermediate disturbance hypothesis (but see [23]). Nevertheless, the hypothesis remains controversial $[10,24]$ and is not well supported for terrestrial animals [25] or benthic marine organisms on soft bottoms [26-28]. Even in tropical forests, the intermediate disturbance hypothesis explains only a small proportion of the variance in plant species richness [21].

Spatial heterogeneity is an often-overlooked alternative to the intermediate disturbance hypothesis. Moderate disturbance may increase spatial heterogeneity, which in turn should lead to more successional states and realized niche space. Either way, intermediate disturbance should, in theory, lead to increased species diversity [1,29-31]. Ant communities in a disturbed landscape provide an example.

At first glance, ant species richness on the Fall-line Sandhills of west-central Georgia in the southeastern United States appears to fit the intermediate disturbance hypothesis. We found that species richness peaked in locales moderately disturbed by military training [32] (Figure 3). But spatial heterogeneity also peaked with intermediate disturbance, and species richness increased linearly with spatial heterogeneity. Either hypothesis (intermediate disturbance or spatial heterogeneity) alone or both hypotheses together could explain the relationship between species richness and disturbance. Consequently, we were unable to distinguish between them.

Intermediate disturbance may generate high spatial heterogeneity, but only if an environment is homogenous to begin with. If an environment is already heterogeneous, disturbance may make it less so. Moreover, extreme disturbance can replace one homogeneous habitat with a different one, 
as when grassland replaces forest following fire. Again, our work on ant communities provides an example.

Ant communities in the Fall-line Sandhills demonstrate how spatial heterogeneity peaks with intermediate disturbance [32]. Undisturbed forest contained few patches and was relatively homogeneous, consisting of either continuous oak-hickory deciduous forest or mixed pine-oak forest [33]. Highly disturbed military-training areas were also homogeneous, having had nearly all trees and A-horizon soil removed. Areas having moderate disturbance, and high ant diversity, were a mosaic of remnant forest-habitat islands surrounded by newly created open patches of bare ground or low-lying shrub/grass cover.

2.2. Species Richness and Predation/Herbivory. The intermediate predation hypothesis is conceptually similar to the intermediate disturbance hypothesis $[16,34]$. Intermediate predation (or herbivory) prevents competitively dominant prey from monopolizing resources, in the same way that physical disturbance does. Species richness is maximized at some intermediate rate of predation or herbivory.

Following work in the rocky marine intertidal zone of the Pacific Northwest of the United States, Robert Paine [35] first recognized that predation could influence local species richness. He found that species richness was highest when a predatory starfish (Pisaster ochraceus) prevented barnacles and mussels from monopolizing the limiting resourcespace. When Paine physically removed all starfish from a plot, the barnacles and mussels competitively excluded several species of limpets, other bivalves, and chitons, reducing species richness and trophic complexity. Paine and Vadas [36] extended the initial generalization, predicting that overexploitation "should lead to a reduced species group .... and eventually, under extreme grazing pressure, all inhabitants should be eliminated.... Between these extremes, a greater number of species should occur." (page 710).

Also working in the rocky marine intertidal zone, but with herbivorous snails and algae, Lubchenco [37] found that the highest species richness of algae occurred at intermediate densities of the snail (Littorina littorea), but only when Littorina preferred grazing on the competitive dominant, Ulva intestinalis. At low snail densities, Ulva monopolized all of the available space. At high snail densities, the snails eliminated all of the palatable algae, leaving only the less palatable species, such as Chondrus crispus. At intermediate snail densities, the snails removed just enough of the Ulva to prevent competitive exclusion. This is a clear example of a unimodal species richness-predation/herbivory curve. When Littorina preferred the competitively inferior species, then species richness declined with increasing predation, generating a monotonic curve.

Lubchenco $[37,38]$ concluded that the specific pattern, unimodal or monotonic, would depend, in part, upon the particular mixture of algae and herbivores. Unimodal patterns should emerge when there are strict competitive hierarchies among plants. Monotonically decreasing patterns should emerge when there is either no competition or when networks of competitive interactions are nontransitive.
Consequently, the generality of unimodal species richnessherbivory curves depends upon the relative occurrences of transitive and nontransitive competitive interactions. This argument should hold for animals and their predators, as well as for plants, algae, and their herbivores.

2.3. Species Richness and Productivity. At local scales, species richness often increases with increasing productivity and then decreases as productivity increases further [39]. Nevertheless, there is considerable debate regarding the frequency of such unimodal species richness-productivity relationships $[6,7,9,40]$. Estimates involving plant communities range from 20 to $52 \%$ of studies, depending on the criteria used and the studies selected [7]. A recent forum published in Ecology, entitled "Evidence and inference: shapes of species richness-productivity curves," attracted 9 contributors [8] in a spirited discussion of the meta-analyses that have broached the subject.

A unimodal species richness-productivity curve consists of increasing and decreasing phases. Rosenzweig and Abramsky [39] summarized the proposed mechanisms for these two phases of the relationship. At the low end of the increase phase, resources are unable to support the rarest species; species richness is low. As productivity increases, more species can coexist, up to a point where the number of species begins to decrease because of competition. At the high end of the decrease phase, a few highly competitive species monopolize all of the resources. In this view, competition drives both sides of the function-competition for scarce resources at the low end and competition with competitively dominant species for abundant resources at the high end.

All studies of the species richness-productivity relationship face the difficult problem of actually measuring net primary productivity (NPP), the rate of conversion of resources to biomass per unit area per unit time [41]. Because NPP is difficult to estimate, biomass, rainfall, evapotranspiration, Normalized Difference Vegetation Index (NDVI), and vegetation height have been used as surrogates. Unfortunately, these surrogates are only roughly indicative of NPP [42]; the relationships between the surrogate measures and NPP are sometimes nonlinear [43].

In addition to the problem of estimating NPP, the relationship between species richness and productivity is complicated by the inverse relationship; productivity is also functionally dependent on species richness. According to Tilman et al. [44], species richness of plants influences productivity and loss of soil nutrients. Despite much independent supporting evidence [45-48], this hypothesis is still controversial and some authors do not believe it has been demonstrated conclusively [49].

Although both species richness-productivity and productivity-species richness-relationships are functions, they are surely not inverse functions. First, if the species richness-productivity function is unimodal, then the inverse productivity-species richness-relationship is not a function (by definition, since it would have two values for each argument). Second, the effect of productivity on species richness is likely to differ substantially from the effect of richness on productivity. 


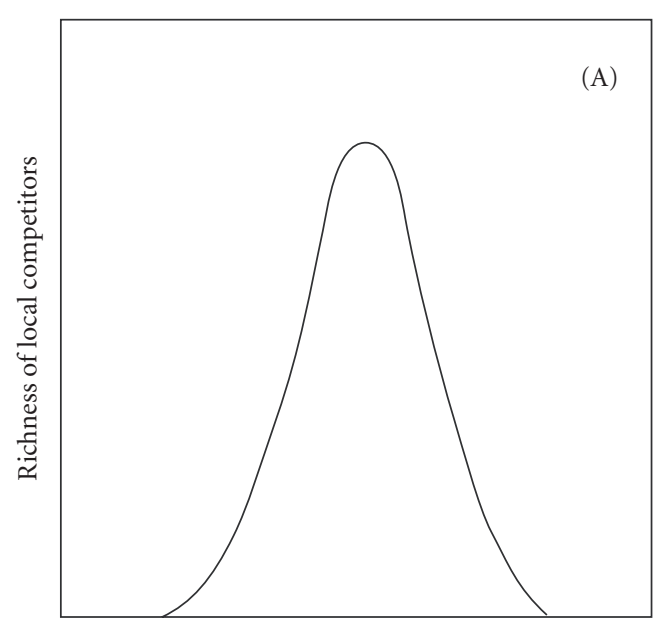

Resource supply rate

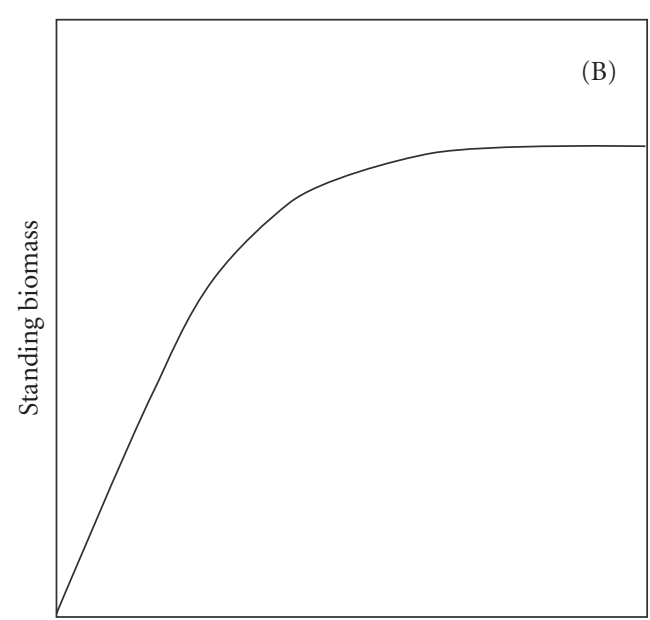

Richness of colonist pool

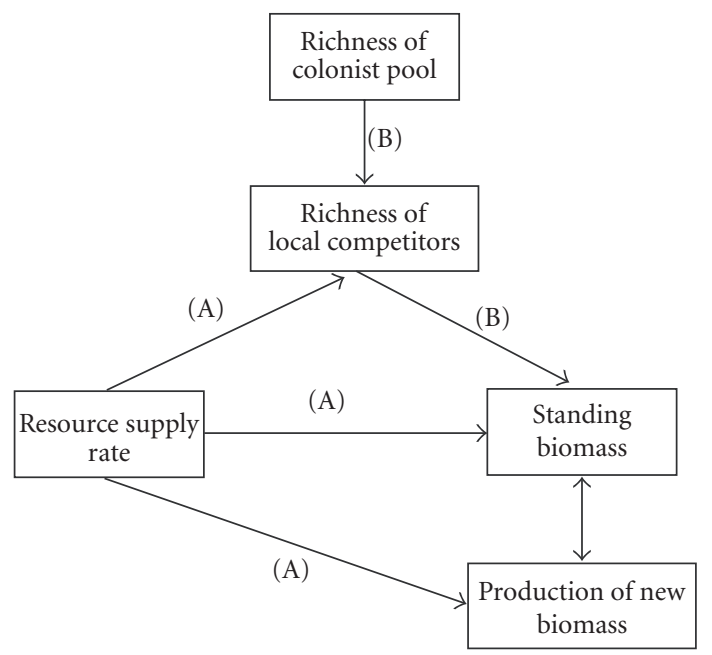

Figure 4: The multivariate productivity-diversity (MPD) hypothesis (redrawn from Cardinale et al. [52]).

If productivity positively affects species richness [50] and species richness in turn positively affects productivity [44], then both species richness and productivity should increase exponentially as long as both feedbacks are positive. To put a brake on the growth, at least one of the feedback links must decline to zero or reverse itself. To escape this apparent contradiction, Gross and Cardinale [51] proposed the multivariate productivity-diversity hypothesis (MPD).

The MPD hypothesis presents species richness in the context of a metacommunity model [51]. It partitions components of species richness into regional (colonists) and local (competitors) pools (or spatial scales), which respond to different drivers (see Section 3). Resource supply rate (i.e., abiotic control or limiting factors) influences the species richness of local competitors while standing biomass influences the richness of the larger metacommunity (Figure 4). It is unclear whether the relationship is simply a matter of scale, with productivity driving species richness at the local "patch" scale and richness driving productivity at the metacommunity scale or whether, as the modeling suggests, both directions occur simultaneously.
To test the MPD hypothesis, Cardinale et al. [52] used nutrient-diffusing substrates (NUDS) spiked with different concentrations of nitrogen and phosphorous in 20 streams in the Sierra Nevada of California, USA. Periphyton colonized the NUDS and a control over a two-month period. The regional pool of colonizers was estimated from natural substrates near the NUDS. Cardinale and colleagues found that despite differences in diatom assemblages across sites, there was a humpbacked species richness-relationship to nutrient concentration across most sites. Furthermore, patches that had higher species richness also had higher biomass and gross primary production. A structural equation model showed that the MDP model explained the covariance of the data better than competing models, which were composed of variables describing local conditions.

Wimp et al. [50] examined arthropod diversity-productivity relationships by experimentally enriching saltmarsh plots containing a monoculture of marsh cordgrass (Spartina alterniflora) at low or high levels. By working within a monoculture, they avoided confounding NPP and habitat composition or structure. Nitrogen fertilization increased 
plant biomass (by 33\% in the low treatment and 52\% in the high treatment) and nitrogen content. Species richness and abundance of the arthropod community increased, with the increase seen across functional feeding groups.

For a variety of reasons, the relationship between species richness and productivity is also likely to exhibit hysteresis, the dependence of a system's state (i.e., species richness) on its history. Alternative stable states, lags, feedback, and nonlinearity contribute to hysteresis. If, for example, productivity begins increasing from some low value, species richness does not immediately increase because the arrival and establishment of new species take considerable time. The same is true if productivity decreases from some high value. The system is said to exhibit path dependence; the curves differ depending upon whether the driver (i.e., productivity) is increasing or decreasing. Low productivity and high productivity states are stable up to a threshold.

Returning to our study of ant communities [32], we find more correlated independent variables (Figure 3). NDVI, a surrogate measure of NPP, decreases linearly with disturbance. Therefore, the intermediate productivity hypothesis can also account for the unimodal species richness-curve of ants on the Fall-line Sandhills. Moreover, the product of NDVI and the fraction of days the maximum soil temperature exceeds $25^{\circ} \mathrm{C}$ (a variable we call available NPP because most ants forage more efficiently at higher temperatures) peaks at intermediate levels of disturbance. Thus, available NPP can account for ant species richness as well. In a stepwise multiple regression of species richness on NDVI, spatial heterogeneity, and soil temperature, only spatial heterogeneity emerged from the selection process. This underscores the complexity of most species richness-relationships.

\subsection{Species Richness and Environmental Gradients. Extreme} environments can often generate unimodal relationships if the gradient is wide enough to be stressful at either extreme $[15,53]$.

Acid-base relationships are often stressful at their extremes. Grime [15], for example, described a humpbacked relationship of herbaceous plant species across a range of soil $\mathrm{pH}$ (3.1 to 7.5). Both mean species density (mean number of species per $\mathrm{m}^{2}$ ) and the total number of species per $\mathrm{pH}$ bin peaked at a $\mathrm{pH}$ of 6.1-6.5. Likewise, Graham [54] showed that species richness of freshwater fishes in New Jersey lakes peaked at a $\mathrm{pH}$ of 7.3 (range 4.1 to 9.1), after removing the effect of lake area (Figure 5). In addition to the stress of extreme $\mathrm{pH}$, productivity varies across a $\mathrm{pH}$ gradient. In acidic blackwaters, the entire food web shifts from one based upon primary producers to one based upon detritus. In alkaline marl lakes, phosphorus coprecipitates with calcium carbonate, reducing fertility [55].

Species richness often peaks in the middle of spatial gradients of elevation and depth [56]. Nearly half of all elevation gradients, for example, may show a mid-elevation peak [57]. Organisms showing mid-elevation peaks in species richness include epiphytic ferns [58], vascular plants and lichens [59], moths [60], ants $[61,62]$, birds $[58,63]$, and small mammals [64]. The reasons for these patterns are varied and difficult to

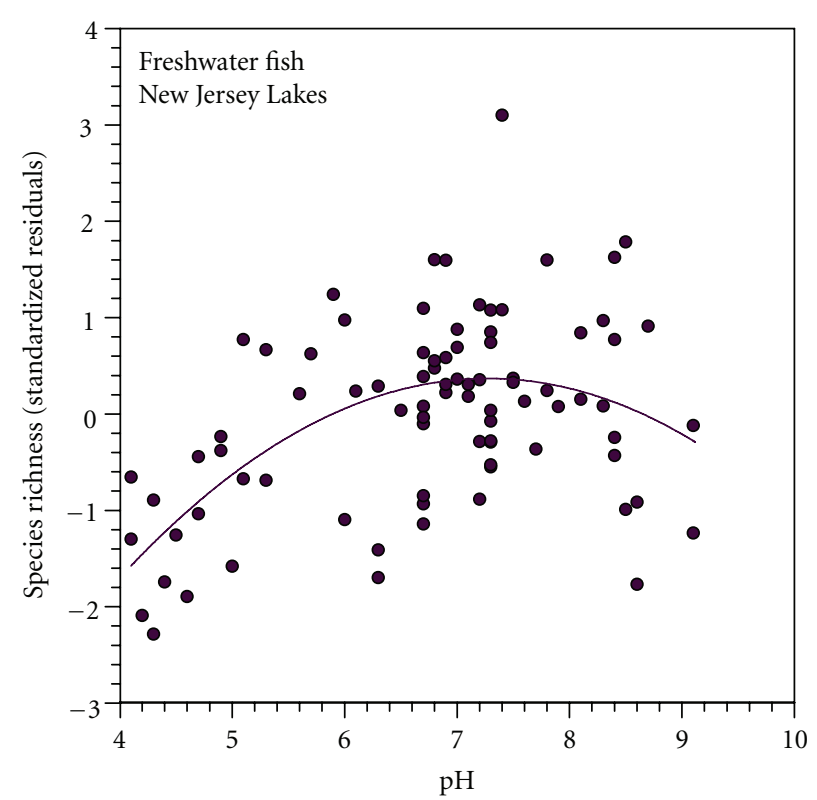

FIGURE 5: Quadratic regression of species richness on $\mathrm{pH}$ for freshwater fishes in $85 \mathrm{New}$ Jersey ponds and lakes, after removing the effect of lake area. After Graham [54].

disentangle. Rapoport's rule, the tendency for species ranges to increase with elevation, can explain some of the humpback curves in moths [60] and ants [61] on elevation gradients. In addition, declining species pool and decreasing intensity of competition with elevation can generate unimodal diversity curves [59].

Environmental and spatial gradients, such as those associated with soil or aquatic $\mathrm{pH}$, elevation, and depth, can vary in productivity [39], disturbance, and spatial heterogeneity. According to Kessler et al. [58], for example, the mid-elevation peak in bird and epiphytic fern diversity in the Bolivian Andes coincides with peaks in primary productivity, foliage height (i.e., spatial heterogeneity), and land use (i.e., disturbance).

In addition to the difficulty in assigning cause and effect, humpback species richness-curves can arise from geometric constraints on species range boundaries in an environmentally homogeneous area $[60,65]$. Randomly placing species on a bounded map produces a peak of species richness near the center of the map. This is the mid-domain effect (MDE), which serves as a null model for species richness on environmental gradients. Before attributing a unimodal species richness-curve to gradients of elevation, depth, $\mathrm{pH}$, productivity, or disturbance, the MDE needs to be addressed (but see [56]).

Finally, species richness of different taxonomic and functional groups can peak at different locations on an environmental gradient. In alpine plant communities of Norway and Finland, for example, species richness of dwarf shrubs peaks at a lower elevation than the species richness of lichens and graminoids, and the species richness of all three of these taxonomic groups peaks at a lower elevation than that of forbs [59]. In freshwater fish communities of New Jersey, species richness of native species and sunfishes 
(Centrarchidae) peaks at a lower $\mathrm{pH}$ than exotic species and minnows (Cyprinidae) [54].

2.5. Species Richness and Time (Succession). Margalef [1] and Horn [66] suggested that species diversity (richness and evenness) peaks during the early or middle stages of succession. Research has not, however, always supported this generalization. Three examples demonstrate the point. A 250-year successional series, from old-field annuals and perennials, to pine, and oak-hickory woodland, on the Georgia Piedmont shows plant species richness increasing and eventually flattening out with no apparent decrease [67]. A 60-year successional sequence culminating in prairie and oak savanna at the Cedar Creek Natural History Area in Minnesota also shows plant species richness increasing continuously with no hump [68]. Species richness of ants on a 130 -year series of coastal dunes also increases monotonically [69]. The reasons for such monotonic relationships are difficult to understand; the ratio of productivity to biomass usually increases and then decreases during succession, as does spatial heterogeneity [66]. Both patterns, if present, should generate unimodal species richness-curves in a long successional series.

2.6. Species Richness and Narrow Latitudinal Gradients. Species richness of most taxonomic and functional groups decreases monotonically from the equator to the poles [70]. Modal relationships (9\% of 191 studies of distinct taxonomic groups) are mostly associated with narrow $\left(<20^{\circ}\right)$ latitudinal gradients, indicating strong scale dependence [70] (see below). Parasitic wasps of the family Ichneumonidae are an exception.

Species richness of North American ichneumonids peaks between $38^{\circ}$ and $42^{\circ} \mathrm{N}$ [71] (Figure 6). According to Janzen, resource fragmentation can explain the pattern. As the diversity of the Ichneumonid's lepidopteran hosts increases toward the tropics, their average population decreases until most Lepidoptera are too rare to support a specialist parasitoid. Alternatively, tropical Lepidoptera may be more distasteful, on average, than temperate Lepidoptera (nasty-host hypothesis) or predation on parasitoids may be more intense in the tropics. Sime and Brower [72] found that the data support the nasty-host hypothesis better than either the resource fragmentation or predation hypotheses.

\section{Scale}

Scale is a necessary component of ecological theory [73]. The response of dependent variables, for example, can change across multiple spatial and temporal scales $[74,75]$. The three components of scale are grain, focus, and extent [12]. The grain is the sampling unit. In our studies of ant communities at Fort Benning, the grain was a $28 \mathrm{~m}^{2}$ area containing 5 pitfall traps whose contents were pooled. The focus is an aggregation of sampling units for which inference is made. At Fort Benning, the focus was a 4 ha site of homogeneous vegetation. The extent is the scale of the entire set of sampling units. At Fort Benning, the extent was the Fall-line Sandhills section of the 73,533 ha military base containing all 40 sites.

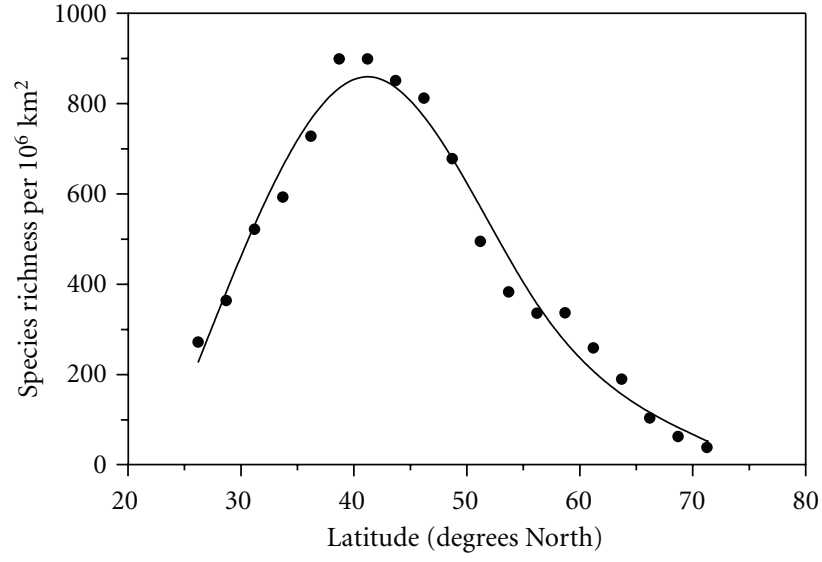

FIgURE 6: Numbers of ichneumonid species per $10^{6} \mathrm{~km}^{2}$ across a latitudinal gradient in North America. Data, from Janzen [71], fit with a natural spline.

Whittaker [76] was among the first to elaborate upon species diversity and scale. He defined three kinds of diversity, which varied according to the scale at which diversity was measured. Alpha diversity is the number of unique species measured within a particular habitat or ecosystem. It is an ecological attribute of a particular place. Beta diversity is the difference in diversity between two or more habitats, expressed as the number of unique species found in each habitat. Beta diversity measures either compositional heterogeneity or the turnover of species among different habitats $[77,78]$, arising from environmental gradients, as well as distance among populations, dispersal of community members, productivity differences, and other elements of structural heterogeneity $[79,80]$. Gamma diversity is the total number of species within a larger region composed of many different habitats. It is a function of alpha diversity and the number of different habitat types present within the larger geographic region.

The drivers of species distribution and abundance can be affected simultaneously, and to differing degrees, by factors operating in nested spatial scales. For example, patterns of amphibian richness and abundance differ among headwater streams grouped according to factors measured at multiple spatial scales [81]. Despite this long recognition, only recently have more papers explicitly dealt with scale effects in examining patterns of species richness [82].

Patterns of species richness are scale dependent [83]. The functional relationship between productivity and species richness, for example, is scale dependent [12]. Part of scale dependence can be attributed to sampling artifacts at local scales [84] or methodological differences among studies occurring at different scales. But recent efforts have explicitly tested for scale dependence by measuring the same variables across scales. Chase and Leibold [85], for example, reported a unimodal relationship of producers and consumers across a productivity gradient at a "local" pond scale, but the relationship was monotonically positive when ponds were compared across watersheds. Other studies have also shown similar scale dependence $[12,41,86]$. Proposed mechanisms responsible for scale dependence include different rates of 
species turnover due to differences in environmental heterogeneity $[85,87]$.

\section{Species Richness-Curves Contingent upon Organism and Environment}

Ecologists have generated a vast literature as they set out to study unimodal species richness-curves for diverse taxa, at multiple spatial and temporal scales, in various biomes. They have done so using observational studies, experimental approaches, or a combination of the two [26]. Additionally, species richness is either the number of species or the species density, and species diversity is one of several indices, including the Shannon index and Hurlbert's probability of interspecific encounter. Likewise, natural disturbances such as waves, fire, and salinity, or anthropogenic stressors such as pollution can be measured along gradients indicating magnitude, frequency, or a combination of the two. Species richness responses can also be a function of productivity, which also has myriad indices or proxies. This diversity in both the dependent and independent variables makes meta-analytic approaches challenging [7]. Below, we briefly survey this literature to provide highlights across major taxa.

4.1. Marine Benthic and Intertidal Organisms. The notion of unimodal species richness-curves arose following seminal work in rocky intertidal zones on Pacific and Atlantic coasts of North America. These studies examined predation and herbivory [36, 37], wave-generated disturbance of substrate and algal communities [88], and storm-generated disturbance of coral reefs $[18,89,90]$. As in other taxonomic groups and ecological systems, tests of unimodal speciesrichness curves in marine benthic and rocky intertidal communities have been observational and experimental. They have also occurred across a range of environmental gradients and spatial scales. Connell's classic intermediate disturbance hypothesis, based on his work with coral reefs, suggested that, under low disturbance, competitive exclusion keeps species richness low because dominant species monopolize resources. Under high disturbance most species are extirpated, leaving moderately disturbed sites with the highest species richness (see also [91]). Similarly, Sousa's [88] study of waves, which frequently turn over small boulders and infrequently damage large boulders, showed that intermediate boulder size had the most biologically diverse communities. He concluded that, although communities may be globally stable, at local scales they are, generally, in nonequilibrium states. A further offshoot of this research is the concept of alternative stable states [92, 93]; large disturbances can cause ecosystems to follow unique trajectories towards different equilibria [94].

Unimodal patterns of species richness are also prevalent in benthic marine communities, with recent studies showing scale dependence and interactions of productivity and disturbance. Species richness of algal communities on the coastline of Sweden was humpbacked along both disturbance (waves) and NPP (biomass) gradients [95]. Jara et al. [96] studied larval settling of macrobenthic marine communities in oligotrophic and eutrophic bays in Brazil. They used a factorial design to test the effects of disturbance (biomass removal) and nutrient enrichment and found that the unimodal relationship was damped in the oligotrophic, but not in the eutrophic, bays (see also [97]).

The interaction between productivity and disturbance may alter the location of the mode (i.e., the dynamic equilibrium hypothesis of Huston [98]) or the form of the unimodal species richness-function [99]. Moreover, complex interactions may occur when both bottom-up (productivity) and top-down (disturbance/consumers) processes are acting simultaneously. These interactions, however, are not always evident; nutrient enrichment in a marine ecosystem on the west coast of Sweden had no effect on unimodal species richnesspatterns [100].

Although our focus in this review is at the local scale, species richness increases from the poles to the equator at a global scale [70]. Witman et al. [101] studied diversity of epifaunal invertebrates on vertical rock walls in 12 regions spread across the globe, with multiple sites sampled locally in each biogeographic region. They found that unimodal species richness-latitude patterns occurred at both local and regional scales, with a more pronounced relationship at regional scales. Importantly, they showed that up to $73 \%$ of the variation in local diversity could be explained by the size of the regional species pool. This strong effect of regional species pools on local diversity has also been seen for coral reefs [102] and serpentine plants [103].

4.2. Marine and Lacustrine Phytoplankton and Zooplankton. The description of patterns of diversity in the plankton has progressed in earnest since Hutchinson [104] introduced his "paradox of the plankton"-why had competitive exclusion not reduced the number of plankton species typically seen in aquatic systems? These systems typically have few limiting resources and theory predicts that the best competitors should monopolize resources.

Like the global distribution of study sites reported by Whitman for benthic macrofauna, Irigoien et al. [105] examined patterns of phytoplankton and zooplankton species diversity against global productivity gradients. Using biomass of these communities as a proxy for productivity, they found unimodal diversity-productivity relationships (Shannon index) for both phytoplankton and zooplankton. Contrary to expectation, however, zooplankton, and phytoplankton biomass were uncorrelated. The unimodal relationship held despite other regulatory gradients, such as light and temperature, that differed among sites.

Lacustrine species richness is affected by primary productivity and lake area. Dodson et al. [106], for example, examined diversity-productivity relationships in 33 lakes, while using lake area as a covariate. They found unimodal species richness-productivity relationships for phytoplankton and zooplankton (rotifers, cladocerans, and copepods), but not for fish. Lake size was a significant covariate for the species richness of fish and phytoplankton.

The diversity-productivity relationship is not consistently unimodal within and among trophic levels. Cohen [107] did not find support for the intermediate disturbance hypothesis; species richness of ostracods declined with 
increasing sedimentation in an African lake known for high levels of ostracod endemism.

In some cases, assembly history can change a unimodal species richness-productivity curve into something else. As immigration and emigration among metapopulations or metacommunities occur, the sequence of arrival of different species can play a role in the developing community structure. A 30-generation species richness-productivity experiment, with four assembly sequences of freshwater protozoans and rotifers in five levels of nutrient enrichment (productivity), generated unimodal, positive monotonic, u-shaped, and no relationship forms of the curves [45].

4.3. Marine and Lacustrine Vertebrates. The emergence of unimodal species richness-curves in lacustrine fish communities is complicated by the effect of lake area on species richness, a phenomenon predicted by the theory of island biogeography $[108,109]$ as well as scale-dependent habitat diversity [110].

As mentioned previously, species richness of native freshwater fish species shows a unimodal relationship on a $\mathrm{pH}$ gradient after the effect of lake area is removed [54]. Species richness is greatest at a $\mathrm{pH}$ of 7.3. Exotic species show a mostly linear relationship, though there is a hint of a decline at the highest $\mathrm{pH}$ (9.1). The $\mathrm{pH}$ of each lake is related to productivity, though the relationship is likely to be complex.

4.4. Terrestrial Plants. According to Tilman and Pacala [111], plant species richness is a unimodal function of productivity. In 1993, these authors could not find a single example of a monotonic relationship between plant species richness and productivity. Since then, the numbers of unimodal relationships have been downgraded considerably. A series of three meta-analyses estimated the percentage of unimodal species richness-productivity relationships in studies of vascular plants to be $41-45 \%$ [40], 20-25\% (landscape to local scales) [112], and 35\% [113]. According to Whittaker's [7] critical review of these species richness-productivity studies, 35 of 68 studies (51.5\%) were deemed inadmissible because they did not meet selection criteria. Of the 15 admissible studies, 7 (or $46.7 \%$ ) were unimodal.

Unimodal species richness-disturbance relationships have been just as contentious, even in the tropical rain forests first promoted as examples of the intermediate disturbance hypothesis by Connell [18]. Bongers et al. [21], for example, examined a large data set of 2504 one-hectare plots $(331,567$ trees) in wet, moist, and dry tropical forests of Ghana. For an index of disturbance they used the percentage of stems in a stand that belonged to pioneer species (range less than $2 \%$ to more than 90\%). Even with huge sample sizes, the unimodal relationships were barely obvious, especially in wet and moist forest. The unimodal curve was best developed in dry tropical forest but only explained $12.3 \%$ of the variance in species density. In the wet forests it only explained an inconsequential $2.8 \%$ of the variance.

4.5. Terrestrial Vertebrates. There are few examples of humpbacked species richness-relationships among terrestrial animals, particularly terrestrial vertebrates [25]. According to
Fuentes and Jaksić [25], most terrestrial animals (both vertebrates and invertebrates) do not meet the three conditions necessary for a unimodal curve of species richness. First, the predator or disturbance must reduce densities of competing species, releasing resources. Second, there must be a large species pool available to colonize the resources that have been released. Third, there must be strong competition among the colonizing species. This occurs with the invertebrates and attached algae of the rocky intertidal zone studied by Connell [18], Paine [35, 36], and Lubchenco [37]. Terrestrial predators and herbivores, however, rarely reduce prey densities to the point that resources are released. And when there is a reduction in prey densities, colonization reconstitutes the original set of species from neighboring habitats. Highly mobile animals can quickly "diffuse" into cleared patches, violating the first condition. Finally, strong competition is reduced by resource partitioning [25]. Invertebrates of the rocky intertidal zone compete for space in two dimensions; most terrestrial animals compete for space in three dimensions. Terrestrial animals also compete for food. Hence, it is easier to partition resources when there are more than two dimensions.

4.6. Terrestrial Invertebrates. The same arguments apply to most terrestrial invertebrates. Fuentes and Jaksić [25], however, have suggested that ants should display unimodal species richness-curves. Ants possess the three criteria necessary for a humpbacked species diversity curve. First, disturbances, such as clear-cuts, substantially reduce their abundance. In Finland, for example, wood ant communities undergo collapse shortly after clear-cutting [114]. In northwestern Georgia, we have found pitfall traps nearly devoid of ants following a clear-cut, while those in neighboring reference sites retain a large ant community (unpublished data, J. H. Graham). They do not immediately diffuse back into the cleared patch. Second, winged queens are available to establish new colonies following a clear-cut [114]. Finally, colonizing species of ants compete strongly. Most ant colonies have a regular spatial distribution, indicative of strong competition for space [115]. In fact, ants show pronounced humpbacked species richness-curves, both for disturbance and productivity (as measured by NDVI) (Figure 3) [32, 116].

Humpbacked diversity patterns in local ant communities have been documented along gradients of both stress [117] and disturbance $[118,119]$, with a reduction in diversity linked to exclusion by dominant species (see also [120]). Andersen [117] actually used the frequencies of dominant ants as surrogates for available productivity, under the assumption that competitively dominant species should prevail in resource-rich environments.

Humpback species richness-curves are difficult to find in terrestrial invertebrates other than ants. This is surprising, especially for herbivorous insects, because one might expect herbivore richness to track plant species richness. Humpbacked species richness-curves are well documented in terrestrial plants, and experimental work by Siemann et al. [121] and Haddad et al. [122, 123] suggests that plant structural and species diversity is positively associated with 
arthropod diversity. Tree species diversity also influences the diversity of herbivorous insects [124]. Logically, then, one would expect a unimodal plant richness curve to generate a unimodal arthropod richness curve. But the relationship between plant and arthropod species richness is weak [121], and patterns evident in field experiments may be masked by noise in real communities. Oddly enough, tree species diversity on Barro Colorado Island, Panama, does not influence the diversity of ants and mites of the leaf litter [125].

Does arthropod diversity fit the intermediate disturbance hypothesis? Some studies of arthropods, especially ants, seem to support it $[119,126,127]$, whereas others do not [128131] or do so for only a few taxa [132]. Thus, arthropods other than ants may, or may not, exhibit intermediate disturbance effects.

4.7. Microorganisms. Do microorganisms show unimodal species richness-curves? According to Smith [46], a literature survey of microbial diversity-productivity relationships from 70 natural, experimental, and engineered aquatic ecosystems reveals mostly unimodal and monotonic patterns (both positive and negative). The unimodal curves accounted for $34.9 \%$ of the natural ecosystems $(n=43)$ and $14.8 \%$ of the experimental and engineered ones $(n=27)$. In both cases, monotonic patterns outnumbered unimodal ones.

\section{Mathematical and Statistical Considerations}

5.1. Polynomial Regression and Data Smoothing. One can fit unimodal functions most simply with a quadratic polynomial $f(x)=a x^{2}+b x+c$. In fact, polynomial regression is especially useful for distinguishing among monotonic (linear), unimodal (quadratic), and multimodal (cubic, quartic, etc.) functions. Nonlinear response models (Huisman-OlffFresco or HOF models $[133,134])$ have also been used to model species richness-curves [21]. For all of these models, however, care must be taken that the mode lies within the range of the data [7]. Alternatively, a variety of data smoothing techniques are available, such as moving averages and locally weighted least squares, or LOESS [135] (see Smith [46] for an example). Despite not generating an equation, or providing a statistical test, data smoothing has the advantage of approximating any curve.

Restricting the range of the independent variable can have dramatic effects on the outcome of a polynomial regression [39]. Sampling below the mode of a unimodal curve generates a relationship that is monotonically increasing, whereas sampling above the mode generates a relationship that is monotonically decreasing. Finally, a very restricted range near the mode may generate no relationship. How widespread is this problem?

Range restriction has shaped the conclusions of our own research. When we began studying species richness of ants at Fort Benning, we selected nine sites in three disturbance classes (light, moderate, and heavy). Species richness seemed to decrease monotonically with increasing disturbance [136]. But when we expanded the study to 40 sites across a much wider range of habitats and disturbance categories (bare ground with widely scattered trees and grasses to deciduous oak-hickory forest) we found the relationship was actually unimodal [32]. Likewise, in Graham's study of species richness of fishes in New Jersey lakes [54], a unimodal relationship would have been unlikely if the lakes in the sample had not had such an unusually wide range of $\mathrm{pH}(4.1-9.1)$.

Many of the positive and negative monotonic relationships described in the literature may represent one-half of a unimodal relationship. It is unlikely that the converse is true. Consequently, it is important to sample across the widest possible range of habitats to get an accurate appraisal of unimodal relationships. Until this is done for a majority of studies, all generalizations are tentative.

5.2. Phylogenetic and Statistical Independence. A group of species may have similar characteristics because they share a recent common ancestor. For example, the size of 10 sunfish species (family Centrarchidae) is, on average, larger than the size of 10 minnows (family Cyprinidae). The size differences are, in part, phylogenetic, and the actual degrees of freedom, if one is trying to compare sizes of fishes in different habitats, are considerably less than $n-2=18$. If one knows the phylogeny (branching order and branch lengths) of a set of species, one can remove the effect of phylogeny. In fact, phylogenetically independent contrasts [137] have been used effectively in studies of species richness and body size [138, 139].

Species richness in ecological communities has its own problems with independence of samples. First, there is the problem of phylogenetic independence, mentioned previously. One community of fishes may consist of 9 centrarchids and a single cyprinid $(S=10)$ while another may consist of 19 cyprinids and a single centrarchid $(S=20)$. Cyprinids as a group are more speciose than centrarchids. Are the differences between the two communities (one community has twice as many species as the other) due to productivity, disturbance, $\mathrm{pH}$, or phylogeny? Methods incorporating phylogenetic information into studies of species richness in ecological communities are still being developed [140].

Clarke and Warwick [141-143] have developed two biodiversity indices based on phylogenetic distance measures. For any data set that includes a list of species with phylogenetic or Linnean classification, the taxonomic diversity is calculated as the path length through the classification tree between randomly chosen individuals, averaged across all possible pairs. Imagine a benthic macro-invertebrate sample having most individuals belonging to the same order (say Diptera) compared with a sample rich in nematodes, plecopterans, trichopterans, ephemeroptera, and dipterans. These two samples could have identical species richness (or abundance and evenness) but would register quite different taxonomic diversity scores. The other related measure is taxonomic distinctness, which divides taxonomic diversity by the minimum value of taxonomic diversity (all species belong to the same genus) [143]. This second measure represents pure taxonomic relatedness, independent of abundance. An interesting property of taxonomic diversity is 
that, unlike other species richness and diversity measures, it is independent of sample size [143]. To our knowledge, explicit testing of unimodal species richness-data with these alternative biodiversity measures has not taken place, although Heino et al. [144] found positive, negative, and neutral correlations across multiple trophic and taxonomic freshwater groups. Additional research into these issues could be fruitful.

There is also the related problem of community composition. Communities are not random collections of species, even if one removes the effect of phylogeny. On a $\mathrm{pH}$ gradient, for example, community composition of fishes changes predictably from acidic blackwaters to alkaline clearwaters [54]. Again, there is a lack of statistical independence. There are more centrarchids in acidic blackwaters and more cyprinids in circumneutral clearwaters. One might try addressing this problem with Felsenstein's [137] method, using an appropriate community similarity (or distance) index and a cluster diagram (branching order and branch length) in place of a cladogram.

\section{Conclusions}

With this admittedly brief review of humpbacked speciesrichness relationships, we sought to describe the history, emerging new theories, and complexities of a topic that encompasses all of ecology. As Lawton [2] suggested, unimodal species richness-relationships may be considered "contingent rules" - contingent on organism and environment, and including all of the caveats and considerations of scale, environment, and organism.

In addition to these considerations, there is the issue of complexity, which we have already touched on. Disturbance and productivity, for example, interact to influence speciesrichness relationships. The actual situation, however, is even more complex, because the interaction of disturbance and productivity varies with trophic level [145]. In productive environments, competitive interactions limit populations of primary producers (plants and algae) and secondary consumers (carnivores). The primary producers compete for space, light, water, and nutrients, and the secondary consumers compete for prey. Secondary consumers, in turn, regulate populations of primary consumers (herbivores), which are not abundant enough to regulate the primary producers. This is the green-world hypothesis of Hairston et al. [146]. In unproductive environments, however, secondary consumers are too rare to regulate primary consumers, which are then regulated by competition for resources. The primary consumers now regulate the primary producers [147]. Consequently, herbivory pressure (a disturbance) should be greatest in the least productive environments, while predation pressure (also a stress, but for a different set of organisms) should be greatest in the most productive environments [145]. At the moment, it is unclear how these three-way interactions among disturbance, productivity, and trophic level will influence species richness.

The latest work to emerge in the field goes beyond merely describing patterns of species richness and experimentally manipulating one independent variable at a time. Disturbance, predation, productivity, succession, environmental gradients, and spatial heterogeneity all influence species richness, and they are all interdependent. The most successful models and experiments will take at least some of these interactions into account, while simultaneously incorporating spatial scale.

Minimally, interactions among disturbance, productivity, and spatial heterogeneity are the most important to understand and the most difficult to accomplish. Jara et al. [96], for example, varied both disturbance and nutrient enrichment. Svensson and colleagues have varied disturbance and productivity [100], different rates of disturbance [148], and different kinds of disturbance with productivity [149]. These are models of what one can accomplish experimentally.

Nevertheless, it is particularly difficult to control, simultaneously, both disturbance and spatial heterogeneity. Fortunately, the relationship between species richness and spatial heterogeneity is likely to be linear. Thus, one could incorporate spatial heterogeneity into manipulative experiments, not as an effect, but as a covariate. Shea et al. [150], in their defense of the intermediate disturbance hypothesis, argued that future research should focus on the underlying mechanisms. This suggestion applies to all studies of species richness, not just those involving disturbance.

\section{Acknowledgments}

The authors thank Catherine Chamberlin-Graham for helping with the literature search and reading an early draft of the paper. Rusty Rodriguez and Sarah Morley reviewed an early version of the paper. They also thank two anonymous reviewers for their comments. J. H. Graham is supported by Berry College.

\section{References}

[1] R. Margalef, "On certain unifying principles in ecology," American Naturalist, vol. 97, pp. 357-374, 1963.

[2] J. H. Lawton, "Are there general laws in ecology?" Oikos, vol. 84, no. 2, pp. 177-192, 1999.

[3] P. J. Morin and J. W. Fox, "Diversity in the deep blue sea," Nature, vol. 429, no. 6994, pp. 813-814, 2004.

[4] S. M. Scheiner and M. R. Willig, "A general theory of ecology," Theoretical Ecology, vol. 1, no. 1, pp. 21-28, 2008.

[5] G. E. Hutchinson, "Homage to Santa Rosalia or why are there so many kinds of animals?" American Naturalist, vol. 93, pp. 145-159, 1959.

[6] P. A. Abrams, "Monotonic or unimodal diversity-productivity gradients: what does competition theory predict?" Ecology, vol. 76, no. 7, pp. 2019-2027, 1995.

[7] R. J. Whittaker, "Meta-analyses and mega-mistakes: calling time on meta-analysis of the species richness-productivity relationship," Ecology, vol. 91, no. 9, pp. 2522-2533, 2010.

[8] D. R. Strong, "Evidence and inference: shapes of species richness-productivity curves," Ecology, vol. 91, no. 9, pp. 2534-2535, 2010.

[9] G. G. Mittelbach, "Understanding species richness-productivity relationships: the importance of meta-analyses," Ecology, vol. 91, no. 9, pp. 2540-2544, 2010. 
[10] R. L. Mackey and D. J. Currie, "The diversity-disturbance relationship: is it generally strong and peaked?" Ecology, vol. 82, no. 12, pp. 3479-3492, 2001.

[11] S. H. Roxburgh, K. Shea, and J. B. Wilson, "The intermediate disturbance hypothesis: patch dynamics and mechanisms of species coexistence," Ecology, vol. 85, no. 2, pp. 359-371, 2004.

[12] S. M. Scheiner and S. Jones, "Diversity, productivity and scale in Wisconsin vegetation," Evolutionary Ecology Research, vol. 4, no. 8, pp. 1097-1117, 2002.

[13] T. Gardezi and J. da Silva, "Diversity in relation to body size in mammals: a comparative study," American Naturalist, vol. 153, no. 1, pp. 110-123, 1999.

[14] M. Huston, Biological Diversity: The Coexistence of Species on Changing Landscapes, Cambridge Unversity Press, Cambridge, UK, 1994.

[15] J. P. Grime, "Control of species density in herbaceous vegetation," Journal of Environmental Management, vol. 1, pp. 151167, 1973.

[16] J. M. Emlen, Ecology: An Evolutionary Approach, AddisonWesley, Reading, Mass, USA, 1973.

[17] H. S. Horn, "Markovian properties of forest succession," in Ecology and Evolution of Communities, M. L. Cody and J. M. Diamond, Eds., pp. 196-211, Belknap Press, Harvard University, Cambridge, Mass, USA, 1975.

[18] J. H. Connell, "Diversity in tropical rain forests and coral reefs," Science, vol. 199, no. 4335, pp. 1302-1310, 1978.

[19] I. Barradas and J. E. Cohen, "Disturbances allow coexistence of competing species," Journal of Mathematical Biology, vol. 32, pp. 663-676, 1994.

[20] P. Chesson, "Mechanisms of maintenance of species diversity," Annual Review of Ecology and Systematics, vol. 31, pp. 343-366, 2000.

[21] F. Bongers, L. Poorter, W. D. Hawthorne, and D. Sheil, "The intermediate disturbance hypothesis applies to tropical forests, but disturbance contributes little to tree diversity," Ecology Letters, vol. 12, no. 8, pp. 798-805, 2009.

[22] J. F. Fox, "Intermediate levels of soil disturbance maximize alpine plant diversity," Nature, vol. 293 , no. 5833 , pp. 564 $565,1981$.

[23] J. E. Tanner, T. P. Hughes, and J. H. Connell, "Species coexistence, keystone species, and succession: a sensitivity analysis," Ecology, vol. 75, no. 8, pp. 2204-2219, 1994.

[24] S. L. Collins and S. M. Glenn, "Intermediate disturbance and its relationship to within- and between-patch dynamics," New Zealand Journal of Ecology, vol. 21, no. 1, pp. 103-110, 1997.

[25] E. R. Fuentes and F. M. Jaksić, "The hump-backed species diversity curve: why has it not been found among land animals?" Oikos, vol. 53, no. 1, pp. 139-143, 1988.

[26] P. R. Cowie, S. Widdicombe, and M. C. Austen, "Effects of physical disturbance on an estuarine intertidal community: field and mesocosm results compared," Marine Biology, vol. 136, no. 3, pp. 485-495, 2000.

[27] M. Huxham, I. Roberts, and J. Bremner, "A field test of the intermediate disturbance hypothesis in the soft-bottom intertidal," International Review of Hydrobiology, vol. 85, no. 4, pp. 379-394, 2000.

[28] T. Garstecki and S. A. Wickham, "The response of benthic rhizopods to sediment disturbance does not support the intermediate disturbance hypothesis," Oikos, vol. 103, no. 3, pp. 528-536, 2003.

[29] R. H. MacArthur and J. W. MacArthur, "On bird species diversity,” Ecology, vol. 42, pp. 594-598, 1961.
[30] R. H. MacArthur, Geographical Ecology: Patterns in The Distribution of Species, Princeton University Press, Princeton, NJ, USA, 1984.

[31] E. R. Pianka, Evolutionary Ecology, Benjamin-Cummings, San Francisco, Calif, USA, 6th edition, 1999.

[32] J. H. Graham, A. J. Krzysik, D. A. Kovacic et al., "Species richness, equitability, and abundance of ants in disturbed landscapes," Ecological Indicators, vol. 9, no. 5, pp. 866-877, 2009.

[33] J. H. Graham, A. J. Krzysik, D. A. Kovacic et al., "Ant community composition across a gradient of disturbed military landscapes at Fort Benning, Georgia," Southeastern Naturalist, vol. 7, no. 3, pp. 429-448, 2008.

[34] A. D. Guerry, Grazing, nutrients, and marine benthic algae: insights into the drivers and protection of diversity, Ph.D. Thesis, Department of Zoology, Oregon State University, Corvallis, Ore, USA, 2006.

[35] R. T. Paine, "Food web complexity and species diversity," American Naturalist, vol. 100, pp. 65-75, 1966.

[36] R. T. Paine and R. L. Vadas, "The effects of grazing by sea urchins, Strongylocentrotus spp., on benthic algal populations," Limnology and Oceanography, vol. 14, pp. 710-719, 1969.

[37] J. Lubchenco, "Plant species diversity in a marine intertidal community: importance of herbivore food preference and algal competitive abilities," American Naturalist, vol. 112, pp. 23-39, 1978.

[38] J. Lubchenco and S. D. Gaines, "A unified approach to marine plant-herbivore interactions. I. populations and communities," Annual Review of Ecology and Systematics, vol. 12, pp. 405-437, 1981.

[39] M. L. Rosenzweig and Z. Abramsky, "How are diversity and productivity related," in Species Diversity in Ecological Communities: Historical and Geographical Perspectives, R. E. Ricklefs and D. Schluter, Eds., pp. 52-65, University of Chicago Press, Chicago, Ill, USA, 1993.

[40] G. G. Mittelbach, C. F. Steiner, S. M. Scheiner et al., "What is the observed relationship between species richness and productivity?" Ecology, vol. 82, no. 9, pp. 2381-2396, 2001.

[41] R. B. Waide, M. R. Willig, C. F. Steiner et al., "The relationship between productivity and species richness," Annual Review of Ecology and Systematics, vol. 30, pp. 257-300, 1999.

[42] E. O. Box, B. N. Holben, and V. Kalb, "Accuracy of the AVHRR vegetation index as a predictor of biomass, primary productivity and net $\mathrm{CO}_{2}$ flux," Vegetatio, vol. 80 , no. 2, pp. 71-89, 1989.

[43] R. J. Whittaker, "In the dragon's den: a response to the metaanalysis forum contributions," Ecology, vol. 91, no. 9, pp. 2568-2571, 2010.

[44] D. Tilman, D. Wedin, and J. Knops, "Productivity and sustainability influenced by biodiversity in grassland ecosystems," Nature, vol. 379, no. 6567, pp. 718-720, 1996.

[45] T. Fukami and P. J. Morin, "Productivity-biodiversity relationships depend on the history of community assembly," Nature, vol. 424, no. 6947, pp. 423-426, 2003.

[46] V. H. Smith, "Microbial diversity-productivity relationships in aquatic ecosystems," FEMS Microbiology Ecology, vol. 62, no. 2, pp. 181-186, 2007.

[47] D. U. Hooper, F. S. Chapin III, J. J. Ewel et al., "Effects of biodiversity on ecosystem functioning: a consensus of current knowledge," Ecological Monographs, vol. 75, no. 1, pp. 3-35, 2005.

[48] R. Ptacnik, A. G. Solimini, T. Andersen et al., "Diversity predicts stability and resource use efficiency in natural phytoplankton communities," Proceedings of the National Academy 
of Sciences of the United States of America, vol. 105, no. 13, pp. 5134-5138, 2008.

[49] M. A. Huston, "Hidden treatments in ecological experiments: re-evaluating the ecosystem function of biodiversity," Oecologia, vol. 110, no. 4, pp. 449-460, 1997.

[50] G. M. Wimp, S. M. Murphy, D. L. Finke, A. F. Huberty, and R. F. Denno, "Increased primary production shifts the structure and composition of a terrestrial arthropod community," Ecology, vol. 91, no. 11, pp. 3303-3311, 2010.

[51] K. Gross and B. J. Cardinale, "Does species richness drive community production or vice versa? Reconciling historical and contemporary paradigms in competitive communities," American Naturalist, vol. 170, no. 2, pp. 207-220, 2007.

[52] B. J. Cardinale, D. M. Bennett, C. E. Nelson, and K. Gross, "Does productivity drive diversity or vice versa? A test of the multivariate productivity-diversity hypothesis in streams," Ecology, vol. 90, no. 5, pp. 1227-1241, 2009.

[53] E. P. Odum, Fundamentals of Ecology, W. B. Saunders, Philadelphia, Pa, USA, 3rd edition, 1971.

[54] J. H. Graham, "Species diversity of fishes in naturally acidic lakes in New Jersey," Transactions of the American Fisheries Society, vol. 122, no. 6, pp. 1043-1057, 1993.

[55] R. G. Wetzel, "Nutritional aspects of algal productivity in marl lakes with particular reference to enrichment bioassays and their interpretation," in Primary Productivity in Aquatic Environments, C. R. Goldman, Ed., pp. 137-157, University of California Press, Berkeley, Calif, USA, 1966.

[56] F. A. Zapata, K. J. Gaston, and S. L. Chown, "Mid-domain models of species richness gradients: assumptions, methods and evidence," Journal of Animal Ecology, vol. 72, no. 4, pp. 677-690, 2003.

[57] C. Rahbek, "The elevational gradient of species richness: a uniform pattern?” Ecography, vol. 18, no. 2, pp. 200-205, 1995.

[58] M. Kessler, S. K. Herzog, J. Fjeldså, and K. Bach, "Species richness and endemism of plant and bird communities along two gradients of elevation, humidity and land use in the Bolivian Andes," Diversity and Distributions, vol. 7, no. 1-2, pp. 61-77, 2001.

[59] H. H. Bruun, J. Moen, R. Virtanen, J. A. Grytnes, L. Oksanen, and A. Angerbjörn, "Effects of altitude and topography on species richness of vascular plants, bryophytes and lichens in alpine communities," Journal of Vegetation Science, vol. 17, no. 1, pp. 37-46, 2006.

[60] G. Brehm, R. K. Colwell, and J. Kluge, "The role of environment and mid-domain effect on moth species richness along a tropical elevational gradient," Global Ecology and Biogeography, vol. 16, no. 2, pp. 205-219, 2007.

[61] N. J. Sanders, "Elevational gradients in ant species richness: area, geometry, and Rapoport's rule," Ecography, vol. 25, no. 1, pp. 25-32, 2002.

[62] N. J. Sanders, J. P. Lessard, M. C. Fitzpatrick, and R. R. Dunn, "Temperature, but not productivity or geometry, predicts elevational diversity gradients in ants across spatial grains," Global Ecology and Biogeography, vol. 16, no. 5, pp. 640-649, 2007.

[63] P. F. Lee, T. S. Ding, F. H. Hsu, and S. Geng, "Breeding bird species richness in Taiwan: distribution on gradients of elevation, primary productivity and urbanization," Journal of Biogeography, vol. 31, no. 2, pp. 307-314, 2004.

[64] C. M. McCain, "The mid-domain effect applied to elevational gradients: species richness of small mammals in Costa Rica," Journal of Biogeography, vol. 31, no. 1, pp. 19-31, 2004.
[65] R. K. Colwell, C. Rahbek, and N. J. Gotelli, "The mid-domain effect and species richness patterns: what have we learned so far?" The American Naturalist, vol. 163, no. 3, pp. E1-E23, 2004.

[66] H. S. Horn, "The ecology of secondary succession," Annual Review of Ecology and Systematics, vol. 5, pp. 25-37, 1974.

[67] S. A. Nicholson and C. D. Monk, "Plant species diversity in old-field succession on the Georgia Piedmont," Ecology, vol. 55, pp. 1075-1085, 1974.

[68] R. S. Inouye, N. J. Huntly, D. Tilman, J. R. Tester, M. Stillwell, and K. C. Zinnel, "Old-field succession on a Minnesota sand plain,” Ecology, vol. 68, no. 1, pp. 12-26, 1987.

[69] J. J. Boomsma and A. J. van Loon, "Structure and diversity of ant communities in successive coastal dune valleys," Journal of Animal Ecology, vol. 51, no. 3, pp. 957-974, 1982.

[70] M. R. Willig, D. M. Kaufman, and R. D. Stevens, "Latitudinal gradients of biodiversity: pattern, process, scale, and synthesis," Annual Review of Ecology, Evolution, and Systematics, vol. 34, pp. 273-309, 2003.

[71] D. H. Janzen, "The peak in North American ichneumonid species richness lies between $38^{\circ}$ and $42^{\circ}$ North," Ecology, vol. 62, pp. 532-537, 1981.

[72] K. R. Sime and A. V. Z. Brower, "Explaining the latitudinal gradient anomaly in ichneumonid species richness: evidence from butterflies," Journal of Animal Ecology, vol. 67, no. 3, pp. 387-399, 1998.

[73] S. A. Levin, "The problem of pattern and scale in ecology: the Robert H. MacArthur award lecture," Ecology, vol. 73, no. 6, pp. 1943-1967, 1992.

[74] D. P. C. Peters, B. T. Bestelmeyer, and M. G. Turner, "Crossscale interactions and changing pattern-process relationships: consequences for system dynamics," Ecosystems, vol. 10, no. 5, pp. 790-796, 2007.

[75] M. A. Leibold, M. Holyoak, N. Mouquet et al., "The metacommunity concept: a framework for multi-scale community ecology," Ecology Letters, vol. 7, no. 7, pp. 601-613, 2004.

[76] R. H. Whittaker, "Evolution and measurement of species diversity," Taxon, vol. 21, pp. 213-251, 1972.

[77] H. Tuomisto, "A diversity of beta diversities: straightening up a concept gone awry-part 1 . Defining beta diversity as a function of alpha and gamma diversity," Ecography, vol. 33, no. 1, pp. 2-22, 2010.

[78] H. Tuomisto, "A diversity of beta diversities: straightening up a concept gone awry-part 2. Quantifying beta diversity and related phenomena," Ecography, vol. 33, no. 1, pp. 23-45, 2010.

[79] C. F. Steiner and M. A. Leibold, "Cyclic assembly trajectories and scale-dependent productivity-diversity relationships," Ecology, vol. 85, no. 1, pp. 107-113, 2004.

[80] M. W. McKnight, P. S. White, R. I. McDonald et al., "Putting beta-diversity on the map: broad-scale congruence and coincidence in the extremes," PLoS Biology, vol. 5, no. 10, pp. 2424-2432, 2007.

[81] H. H. Welsh Jr., G. R. Hodgson, J. J. Duda, and J. M. Emlen, "Faunal assemblages and multi-scale habitat patterns in headwater tributaries of the South Fork Trinity River-an unregulated river embedded within a multiple-use landscape," Animal Biodiversity and Conservation, vol. 33, no. 1, pp. 63-87, 2010.

[82] C. Rahbek, "The role of spatial scale and the perception of large-scale species-richness patterns," Ecology Letters, vol. 8, no. 2, pp. 224-239, 2005. 
[83] S. M. Scheiner, S. B. Cox, M. Willig, G. G. Mittelbach, C. Osenberg, and M. Kaspari, "Species richness, speciesarea curves and Simpson's paradox," Evolutionary Ecology Research, vol. 2, no. 6, pp. 791-802, 2000.

[84] J. Oksanen, "Is the humped relationship between species richness and biomass an artefact due to plot size?" Journal of Ecology, vol. 84, no. 2, pp. 293-295, 1996.

[85] J. M. Chase and M. A. Leibold, "Spatial scale dictates the productivity-biodiversity relationship," Nature, vol. 416, no. 6879, pp. 427-430, 2002.

[86] D. R. Chalcraft, J. W. Williams, M. D. Smith, and M. R. Willig, "Scale dependence in the species-richness-productivity relationship: the role of species turnover," Ecology, vol. 85, no. 10, pp. 2701-2708, 2004.

[87] M. L. Rosenzweig, Species Diversity in Space and Time, Cambridge University Press, Cambridge, UK, 1995.

[88] W. P. Sousa, "Disturbance in marine intertidal boulder fields: the nonequilibrium maintenance of species diversity," Ecology, vol. 60, pp. 1225-1239, 1979.

[89] T. R. McClanahan and S. H. Shafir, "Causes and consequences of sea urchin abundance and diversity in Kenyan coral reef lagoons," Oecologia, vol. 83, no. 3, pp. 362-370, 1990.

[90] C. S. Rogers, "Hurricanes and coral reefs: the intermediate disturbance hypothesis revisited," Coral Reefs, vol. 12, no. 34, pp. 127-137, 1993.

[91] J. H. Connell, T. P. Hughes, and C. C. Wallace, "A 30-year study of coral abundance, recruitment, and disturbance at several scales in space and time," Ecological Monographs, vol. 67, no. 4, pp. 461-488, 1997.

[92] R. M. May, "Thresholds and breakpoints in ecosystems with a multiplicity of stable states," Nature, vol. 269, no. 5628, pp. 471-477, 1977.

[93] A. Schröder, L. Persson, and A. M. de Roos, "Direct experimental evidence for alternative stable states: a review," Oikos, vol. 110, no. 1, pp. 3-19, 2005.

[94] M. Scheffer, S. H. Hosper, M. L. Meijer, B. Moss, and E. Jeppesen, "Alternative equilibria in shallow lakes," Trends in Ecology and Evolution, vol. 8, no. 8, pp. 275-279, 1993.

[95] L. Kautsky and H. Kautsky, "Algal species diversity and dominance along gradients of stress and disturbance in marine environments," Vegetatio, vol. 83, no. 1-2, pp. 259267, 1989.

[96] V. C. Jara, J. H. S. Miyamoto, B. A. P. da Gama, M. Molis, M. Wahl, and R. C. Pereira, "Limited evidence of interactive disturbance and nutrient effects on the diversity of macrobenthic assemblages," Marine Ecology Progress Series, vol. 308, pp. 37-48, 2006.

[97] M. Kondoh, "Unifying the relationships of species richness to productivity and disturbance," Proceedings of the Royal Society $B$, vol. 268, no. 1464, pp. 269-271, 2001.

[98] M. Huston, "A general hypothesis of species diversity," American Naturalist, vol. 113, pp. 81-101, 1979.

[99] B. Worm, H. K. Lotze, H. Hillebrand, and U. Sommer, "Consumer versus resource control of species diversity and ecosystem functioning," Nature, vol. 417, no. 6891, pp. 848-851, 2002.

[100] J. R. Svensson, M. Lindegarth, M. Siccha et al., "Maximum species richness at intermediate frequencies of disturbance: consistency among levels of productivity," Ecology, vol. 88, no. 4, pp. 830-838, 2007.

[101] J. D. Witman, R. J. Etter, and F. Smith, "The relationship between regional and local species diversity in marine benthic communities: a global perspective," Proceedings of the
National Academy of Sciences of the United States of America, vol. 101, no. 44, pp. 15664-15669, 2004.

[102] R. H. Karlson, H. V. Cornell, and T. P. Hughes, "Coral communities are regionally enriched along an oceanic biodiversity gradient," Nature, vol. 429, no. 6994, pp. 867-870, 2004.

[103] S. Harrison, H. D. Safford, J. B. Grace, J. H. Viers, and K. F. Davies, "Regional and local species richness in an insular environment: serpentine plants in California," Ecological Monographs, vol. 76, no. 1, pp. 41-56, 2006.

[104] G. E. Hutchinson, "The paradox of the plankton," American Naturalist, vol. 95, pp. 137-145, 1961.

[105] X. Irigoien, J. Hulsman, and R. P. Harris, "Global biodiversity patterns of marine phytoplankton and zooplankton," Nature, vol. 429, no. 6994, pp. 863-867, 2004.

[106] S. I. Dodson, S. E. Arnott, and K. L. Cottingham, "The relationship in lake communities between primary productivity and species richness," Ecology, vol. 81, no. 10, pp. 2662-2679, 2000.

[107] A. S. Cohen, R. Bills, C. Z. Cocquyt, and A. G. Caljon, "The impact of sediment pollution on biodiversity in Lake Tanganyika," Conservation Biology, vol. 7, no. 3, pp. 667-677, 1993.

[108] R. H. MacArthur and E. O. Wilson, The Theory of Island Biogeography, Princeton University Press, Princeton, NJ, USA, 1967.

[109] J. M. Eadie, T. A. Hurly, R. D. Montgomerie, and K. L. Teather, "Lakes and rivers as islands: species-area relationships in the fish faunas of Ontario," Environmental Biology of Fishes, vol. 15, no. 2, pp. 81-89, 1986.

[110] J. Tews, U. Brose, V. Grimm et al., "Animal species diversity driven by habitat heterogeneity/diversity: the importance of keystone structures," Journal of Biogeography, vol. 31, no. 1, pp. 79-92, 2004.

[111] D. Tilman and S. Pacala, "The maintenance of species richness in plant communities," in Species Diversity in Ecological Communities, R. E. Ricklefs and D. Schluter, Eds., pp. 13-25, University of Chicago Press, Chicago, Ill, USA, 1993.

[112] L. N. Gillman and S. D. Wright, "The influence of productivity on the species richness of plants: a critical assessment," Ecology, vol. 87, no. 5, pp. 1234-1243, 2006.

[113] M. Pärtel, L. Laanisto, and M. Zobel, "Contrasting plant productivity-diversity relationships across latitude: the role of evolutionary history," Ecology, vol. 88, no. 5, pp. 10911097, 2007.

[114] P. Punttila, Y. Haila, T. Pajunen, and H. Tukia, "Colonisation of clearcut forests by ants in the southern Finnish taiga: a quantitative survey," Oikos, vol. 61, no. 2, pp. 250-262, 1991.

[115] B. Hölldobler and E. O. Wilson, The Ants, Belknap Press, Harvard University, Cambridge, Mass, USA, 1990.

[116] T. P. McGlynn, M. D. Weiser, and R. R. Dunn, "More individuals but fewer species: testing the 'more individuals hypothesis' in a diverse tropical fauna," Biology Letters, vol. 6, no. 4, pp. 490-493, 2010.

[117] A. N. Andersen, "Regulation of "momentary" diversity by dominant species in exceptionally rich ant communities of the Australian seasonal tropics," American Naturalist, vol. 140, no. 3, pp. 401-420, 1992.

[118] J. D. Majer, "Recolonization by ants of rehabilitated mineral sand mines on North Stradbroke Island, Queensland, with particular reference to seed removal," Austral Ecology, vol. 10, no. 1, pp. 31-48, 1985.

[119] L. Gallé, "Structure and succession of ant assemblages in a north European sand dune area," Holarctic Ecology, vol. 14, no. 1, pp. 31-37, 1991. 
[120] B. J. Fox, E. Archer, and M. D. Fox, "Ant communities along a moisture gradient," in Proceedings of the 5th International Conference on Mediterranean Ecosystems, F. di Castri, C. Floret, S. Rambal, and J. Roy, Eds., pp. 661-667, International Union of Biological Sciences, Paris, France, 1988.

[121] E. Siemann, D. Tilman, J. Haarstad, and M. Ritchie, "Experimental tests of the dependence of arthropod diversity on plant diversity," American Naturalist, vol. 152, no. 5, pp. 738750, 1998.

[122] N. M. Haddad, D. Tilman, J. Haarstad, M. Ritchie, and J. M. H. Knops, "Contrasting effects of plant richness and composition on insect communities: a field experiment," American Naturalist, vol. 158, no. 1, pp. 17-35, 2001.

[123] N. M. Haddad, G. M. Crutsinger, K. Gross, J. Haarstad, and D. Tilman, "Plant diversity and the stability of foodwebs," Ecology Letters, vol. 14, no. 1, pp. 42-46, 2011.

[124] V. Novotny, P. Drozd, S. E. Miller et al., "Why are there so many species of herbivorous insects in tropical rainforests?" Science, vol. 313, no. 5790, pp. 1115-1118, 2006.

[125] D. A. Donoso, M. K. Johnston, and M. Kaspari, "Trees as templates for tropical litter arthropod diversity," Oecologia, vol. 164, no. 1, pp. 201-211, 2010.

[126] F. Szentkiralyi and F. Kozar, "How many species are there in apple insect communities?: testing the resource diversity and intermediate disturbance hypotheses," Ecological Entomology, vol. 16, no. 4, pp. 491-503, 1991.

[127] T. P. Young, C. H. Stubblefield, and L. A. Isbell, "Ants on swollen-thorn acacias: species coexistence in a simple system," Oecologia, vol. 109, no. 1, pp. 98-107, 1997.

[128] P. J. M. Greenslade and P. Greenslade, "Some effects of vegetation cover and disturbance on a tropical ant fauna," Insectes Sociaux, vol. 24, no. 2, pp. 163-182, 1977.

[129] C. Járdán, L. Gallé, and K. Margóczi, “Ant assemblage composition in a successional Hungarian sand dune area," Tiscia, vol. 27, pp. 9-15, 1993.

[130] J. L. Rambo and S. H. Faeth, "Effect of vertebrate grazing on plant and insect community structure," Conservation Biology, vol. 13, no. 5, pp. 1047-1054, 1999.

[131] A. Floren, A. Freking, M. Biehl, and K. Eduard Linsenmair, "Anthropogenic disturbance changes the structure of arboreal tropical ant communities," Ecography, vol. 24, no. 5, pp. 547-554, 2001.

[132] M. Abensperg-Traun, G. T. Smith, G. W. Arnold, and D. E. Steven, "The effects of habitat fragmentation and livestockgrazing on animal communities in remnants of gimlet Eucalyptus salubris woodland in the Western Australian wheatbelt. I. Arthropods," Journal of Applied Ecology, vol. 33, no. 6, pp. 1281-1301, 1996.

[133] J. Huisman, H. Olff, and L. F. M. Fresco, "A hierarchical set of models for species response analysis," Journal of Vegetation Science, vol. 4, no. 1, pp. 37-46, 1993.

[134] J. Oksanen and P. R. Minchin, "Continuum theory revisited: what shape are species responses along ecological gradients?" Ecological Modelling, vol. 157, no. 2-3, pp. 119-129, 2002.

[135] W. S. Cleveland, "Robust locally weighted regression and smoothing scatterplots," Journal of the American Statistical Association, vol. 74, pp. 829-836, 1979.

[136] J. H. Graham, H. H. Hughie, S. Jones et al., "Habitat disturbance and the diversity and abundance of ants (Formicidae) in the Southeastern Fall-Line Sandhills," Journal of Insect Science, vol. 4, no. 30, pp. 1-15, 2004.

[137] J. Felsenstein, "Phylogenies and the comparative method," American Naturalist, vol. 125, no. 1, pp. 1-15, 1985.
[138] C. D. L. Orme, D. L. J. Quicke, J. M. Cook, and A. Purvis, "Body size does not predict species richness among the metazoan phyla," Journal of Evolutionary Biology, vol. 15, no. 2, pp. 235-247, 2002.

[139] J. D. Olden, Z. S. Hogan, and M. J. V. Zanden, "Small fish, big fish, red fish, blue fish: size-biased extinction risk of the world's freshwater and marine fishes," Global Ecology and Biogeography, vol. 16, no. 6, pp. 694-701, 2007.

[140] C. O. Webb, D. D. Ackerly, M. A. McPeek, and M. J. Donoghue, "Phylogenies and community ecology," Annual Review of Ecology and Systematics, vol. 33, pp. 475-505, 2002.

[141] K. R. Clarke and R. M. Warwick, "A taxonomic distinctness index and its statistical properties," Journal of Applied Ecology, vol. 35, no. 4, pp. 523-531, 1998.

[142] R. M. Warwick and K. R. Clarke, "New 'biodiversity' measures reveal a decrease in taxonomic distinctness with increasing stress," Marine Ecology Progress Series, vol. 129, no. 1-3, pp. 301-305, 1995.

[143] R. M. Warwick and K. R. Clarke, "Taxonomic distinctness and environmental assessment," Journal of Applied Ecology, vol. 35, no. 4, pp. 532-543, 1998.

[144] J. Heino, J. Soininen, J. Lappalainen, and R. Virtanen, "The relationship between species richness and taxonomic distinctness in freshwater organisms," Limnology and Oceanography, vol. 50, no. 3, pp. 978-986, 2005.

[145] L. Oksanen and T. Oksanen, "The logic and realism of the hypothesis of exploitation ecosystems," American Naturalist, vol. 155, no. 6, pp. 703-723, 2000.

[146] N. G. Hairston, F. E. Smith, and L. B. Slobodkin, "Community structure, population control, and competition," American Naturalist, vol. 94, pp. 421-425, 1960.

[147] L. Oksanen, S. D. Fretwell, J. Arruda, and P. Niemelä, "Exploitation ecosystems in gradients of primary productivity," American Naturalist, vol. 118, pp. 240-261, 1981.

[148] J. R. Svensson, M. Lindegarth, and H. Pavia, "Equal rates of disturbance cause different patterns of diversity," Ecology, vol. 90, no. 2, pp. 496-505, 2009.

[149] J. R. Svensson, M. Lindegarth, and H. Pavia, "Physical and biological disturbances interact differently with productivity: effects on floral and faunal richness," Ecology, vol. 91, no. 10, pp. 3069-3080, 2010.

[150] K. Shea, S. H. Roxburgh, and E. S. J. Rauschert, "Moving from pattern to process: coexistence mechanisms under intermediate disturbance regimes," Ecology Letters, vol. 7, no. 6, pp. 491-508, 2004. 

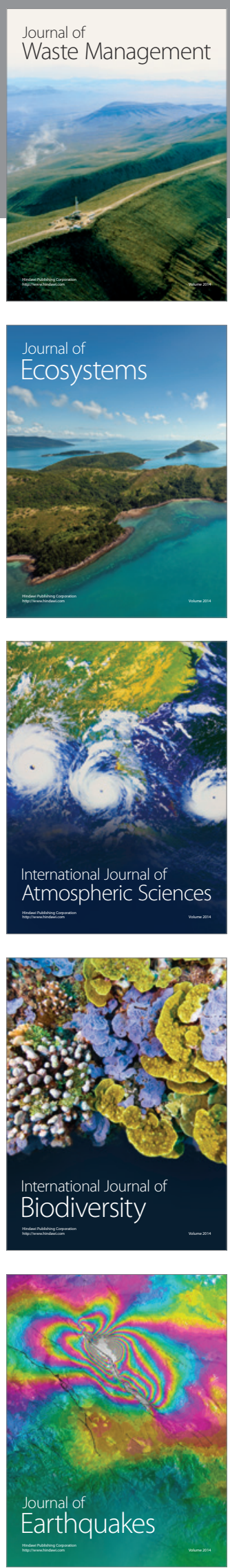
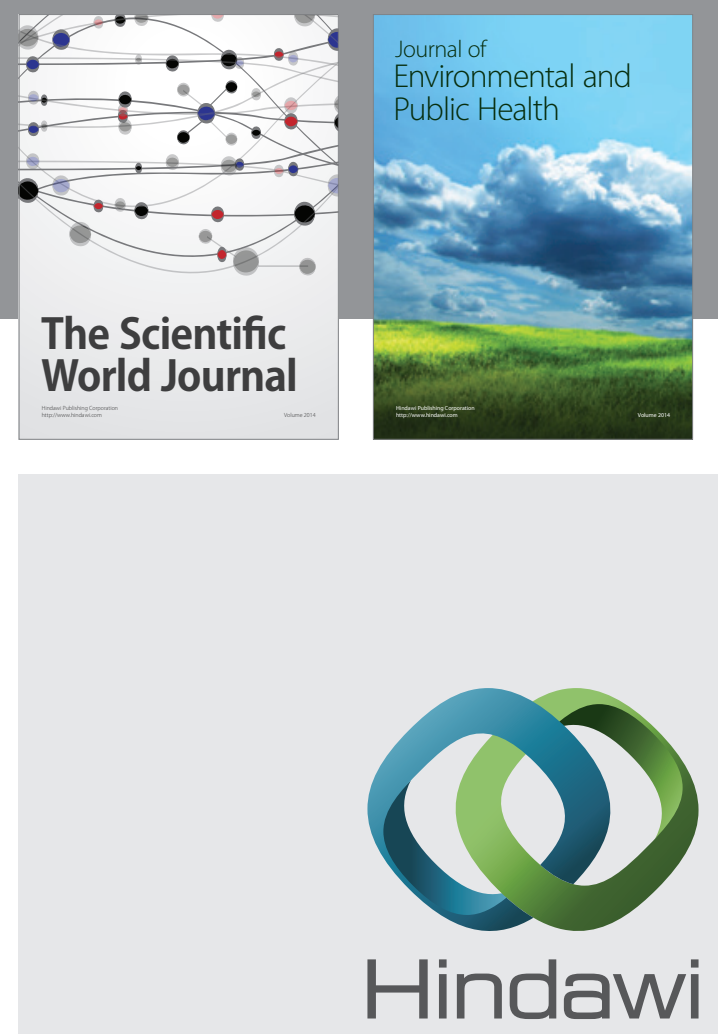

Submit your manuscripts at

http://www.hindawi.com
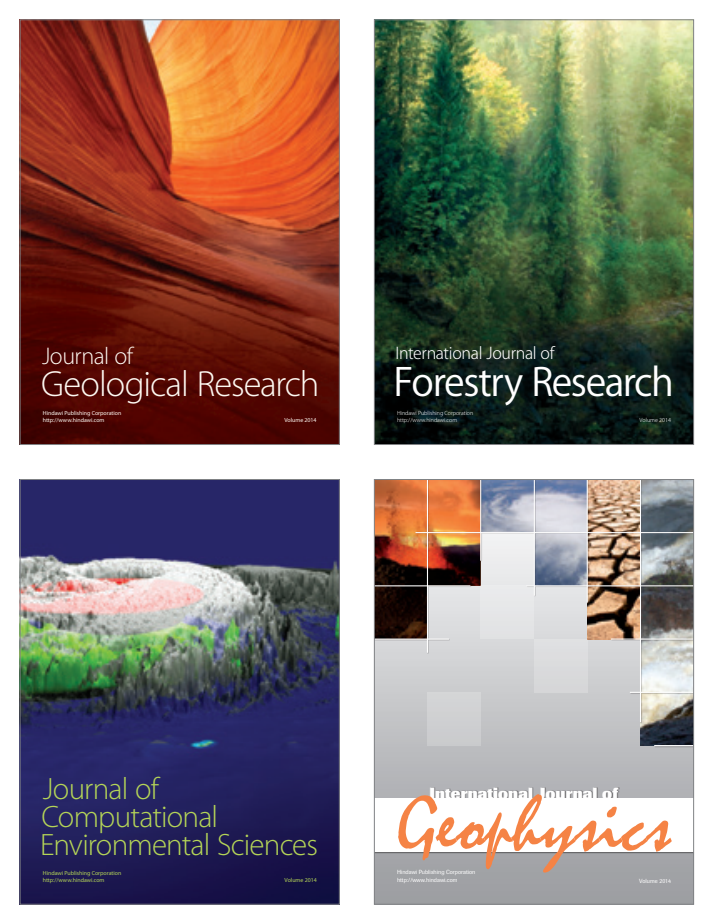
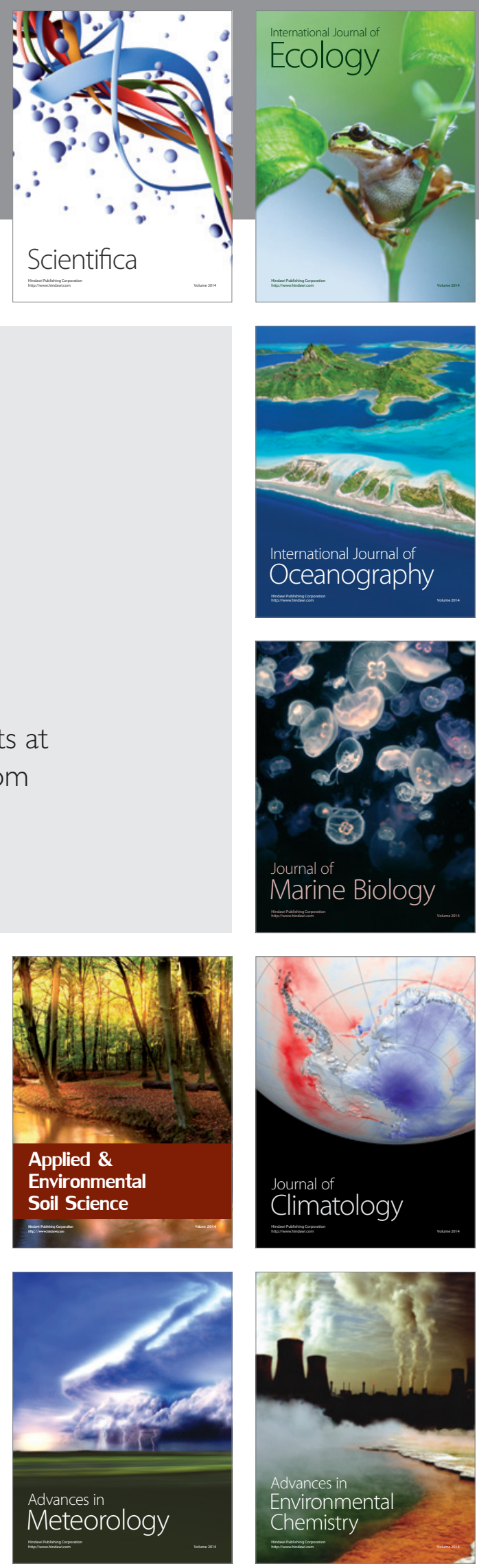